\title{
Respiratory symptoms and lung function effects of domestic exposure to tobacco smoke and cooking by gas in non-smoking women in Singapore
}

\author{
T P Ng, KP Hui, Wan C Tan
}

\begin{abstract}
Study objectives-To investigate the effects of passive exposure to tobacco smoke and gas cooking at home on respiratory symptoms and lung function of non-smoking women. Setting-Evidence on the effects of passive smoking and exposure to nitrogen dioxide from gas cooking on the respiratory health of adults is limited and variable. Over $97 \%$ of women in Singapore do not smoke, and a principal source of indoor air pollution for housewives is passive smoking and gas cooking.

Design-This was a cross sectional (prevalence) study of a population based sample of 2868 adults aged 20 to 74 years in Singapore. A structured questionnaire administered by trained interviewers was used to collect data on passive smoking, gas cooking, respiratory symptoms, and other relevant variables. Passive smoking was defined as exposure to cigarette smoke from one or more members of the household who had ever smoked. Gas cooking was defined in terms of the weekly frequency of gas cooking, as well as the frequency with which the respondent's kitchen was filled with heavy cooking fumes (rarely, occasionally, often). Forced expiratory volume in one second $\left(F E V_{1}\right)$ was measured by using a portable Microspirometer. Multivariate analyses were used to estimate relative odds of association for respiratory symptoms and $\mathrm{FEV}_{1}$ effect, with adjustment for potential confounding variables.
\end{abstract}

Participants-Of a total of 1438 women in the sample, 1282 women who had never smoked provided questionnaire data and 1008 women provided acceptable readings of $F E V_{1}$ for analysis.

Main results-Passive smoking was significantly associated with greater relative odds of usual or chronic cough and phlegm, wheezing, and breathlessness on exertion, as well as lower $\mathrm{FEV}_{1}$. Greater relative odds of respiratory symptoms were also associated with the weekly frequency of gas cooking, although these results were statistically insignificant. Chronic cough and phlegm and breathlessness on exertion, however, were significantly associated with the frequency with which the kitchen was filled with heavy cooking fumes. A lower $F E V_{1}$ was found in women who cooked frequently (more than thrice a week).

Conclusion-Domestic exposure to cigarette smoke and gas cooking is associated with increased risks of respiratory symptoms and impairment of lung function in non-smoking women in Singapore.

\section{f Epidemiol Community Health 1993; 47: 454-459}

Domestic exposure to cigarette smoke ("passive smoking") and to nitrogen dioxide from the use of gas for domestic cooking and heating are two principal sources of indoor air pollution that have been investigated in recent years as environmental causes of respiratory morbidity in people who do not smoke. ${ }^{12}$ Most studies in children have shown that passive smoking is associated with increased frequencies of respiratory illness ${ }^{310}$ and symptoms, ${ }^{11} 14$ and deleterious effects on lung function. ${ }^{14} 21$ The use of gas for cooking or heating has also been shown to be associated with increased frequencies of respiratory symptoms and illnesses in some studies, ${ }^{79} 142223$ but not in others. ${ }^{24-26}$ Gas cooking was found to be associated with only little ${ }^{9220}$ or no ${ }^{8224}$ diminution in lung function in children. There are many fewer reports on the effects of these indoor air pollutants in adults, and the results are also more variable. Passive exposure to tobacco smoke in the home is not associated with respiratory symptoms according to some studies ${ }^{11} 2728$ but positive associations are found in others. ${ }^{29}{ }^{30}$ No association with lung function impairment is reported in some studies, ${ }^{272831}$ but significant impairment is reported in others. ${ }^{32-35}$ The use of gas for cooking or heating is reported to be associated with an increased prevalence of respiratory symptoms ${ }^{28} 3637$ and diminished lung function ${ }^{37} 39$ in adults, although some investigators have also found no adverse respiratory effects. ${ }^{24} 28$

In Singapore, environmental tobacco smoke and nitrogen dioxide from gas cooking are important sources of domestic air pollution, with potentially deleterious effects on respiratory health. This is because most women (about 97\%) are non-smokers. There is widespread prohibition of smoking in workplaces and in all enclosed public spaces such as cinemas, restaurants, hotels, and public transport. Hence, the principal exposure to environmental tobacco smoke in non-smokers occurs at home. Moreover, about half of all women are housewives who are not therefore exposed to pollutants at the workplace, but are likely to be most heavily exposed to environmental tobacco smoke from spouses and other members of the household who smoke. The prevalence of current smokers among the adult male population is about $35 \%$. Because of the warm tropical climate, gas is not used for home heating. Cooking is generally by piped or bottle gas and additionally with electricity. Water for 
showers or baths is heated by electricity, almost never with gas.

This study was undertaken to investigate the relationship between domestic exposure to passive smoking and gas cooking and respiratory symptom prevalence and pulmonary function in a population sample of non-smoking women in Singapore.

\section{Methods}

The subjects in this study were recruited from a population sample survey of respiratory health of male and female adults aged 20 to 74 years in Singapore. A stratified, two stage cluster disproportionate sampling procedure was used to obtain a study sample with approximately equal quotas of subjects for each of the three races (Chinese, Malays, and Indians), and 11 five year age groups. The final sample consisted of 2868 residents $(72.8 \%$ response) in 1866 households (79\% response) drawn from 199 housing blocks in five public housing estates on the island.

A structured questionnaire was administered by trained interviewers in the languages usually understood and spoken by the respondents. In most cases, the interview was conducted in English as most people in Singapore use English in addition to their ethnic language. In cases where older respondents could not understand English, it was always possible to enlist the help of their English speaking children in the household or appropriate interviewers who spoke Chinese, Malay, or Tamil.

Respiratory symptoms were elicted using a modified version of the British Medical Research Council Questionnaire for Chronic Bronchitis. Usual cough or usual phlegm were defined as usually having cough or bringing up phlegm, first thing in the morning or during the day or night, on most days of the week, for the past three years. Chronic cough or phlegm was defined as usual cough or phlegm occurring for as much as three months or more in the year. Breathlessness referred to shortness of breath when walking up a slight incline or hurrying on level ground, or a greater grade of exertional dyspnoea. Asthma was defined as episodic wheeze and report of asthmatic symptoms diagnosed by a doctor as asthma during the past year, in the absence of cardiac disease. Atopy was defined according to the presence of symptoms of chronic rhinitis and eczema related to contact with allergens.

A non-smoker was defined as someone who had never smoked one or more cigarettes a day for as long as a year. Passive smoking was defined in terms of the presence of one or more members (beside the respondent) of the household who was ever a smoker. A respondent was considered to have heavy exposure to passive smoke if one or more members of her household was ever a heavy smoker (past or current daily consumption of 20 or more cigarettes); her exposure was considered light if none of her smoking household members smoked more than 20 cigarettes a day.

Each respondent was asked how many times in a week she usually did cooking at home. Since exposure to nitrogen dioxide from gas cooking might also vary depending on the degree of natural or forced ventilation in the kitchen, an additional question was asked, "How often does your kitchen get filled with heavy cooking fumes?" (rarely, occasionally, often).

Socioeconomic status was defined according to the size of the flat (one to three rooms, four or more rooms) since this is highly related to income, although it should be noted that the socioeconomic differential is not wide in residents of public housing estates. In terms of employment status, women were defined as housewives if they had never been in paid employment.

Pulmonary function was measured using a hand held turbine spirometer (Micro spirometer, Micro Medical Limited) which had been validated previously. ${ }^{4041}$ Each spirometer was calibrated at the beginning of the survey and checked preiodically in series against a dry-wedged, bellows spirometer (Vitalograph), with satisfactory results. The field workers were given prior intensive instruction and training to ensure that the forced expiratory manoeuvres were performed properly by the respondent. At least three "satisfactory" blows were recorded, and the subject's technical performance was assessed by the field worker and readings which were considered "technically unsatisfactory" were discarded. Previous studies indicate, ${ }^{42}$ and the results of our own validation studies also confirm, that the forced vital capacity meaured by the portable spirometer is liable to be systematically underestimated because of insufficient completion of forced expiration without the aid of a graphical presentation of the volume-time curve. For this reason, only the forced expiratory volume in one second $\left(\mathrm{FEV}_{1}\right)$ was used to assess the degree of airway obstruction.

The statistical analysis involved data of 1282 life long, non-smoking women with no known history of cardiac disease from the total of 1438 women in the study sample. Of these, a total of 1008 non-smoking women provided acceptable readings of $\mathrm{FEV}_{1}$ for analysis. $\mathrm{FEV}_{1}$ data were expressed as percentages of predicted values based on age and height, separately for each of the three races. Separate prediction equations for female Chinese, Malays, and Indians were based on the data of non-smoking women without known cardiac or respiratory diseases including asthma and chronic bronchitis in the sample.

In comparing the prevalences of chronic respiratory symptoms and asthma in exposure groups, multiple logistic regression was used to calculate the relative odds of associations and their $95 \%$ confidence intervals $(95 \% \mathrm{CI})$ with simultaneous adjustment for age (20-39, 40-59, 60-74 years), race, area of residence, flat size, and employment status. Relative odds for wheeze and physician-diagnosed asthma were calculated with additional adjustment for chronic rhinitis/eczema. Multiple linear regression was used to assess the independent association of passive smoking and gas cooking with $\mathrm{FEV}_{1}$ and $\mathrm{FEV}_{1} \%$ or predicted with covariate adjustment for age, race, height, area of residence, flat size, and employment status, where appropriate. To exclude the possiblility of workplace exposure to cigarette smoke, the data were also analysed separately for housewives only. The analyses were performed using procedures from the SAS package of statistical softwares. 
Results

The demographic characteristics of the nonsmoking women in the study are shown in table I. Forty three per cent of the women were housewives, and as expected were generally older than women in paid employment. The prevalence of ever having been exposed to passive smoking at home was $52 \%$. Fifty per cent of the women reported cooking three to 14 times a week, and another $29 \%$ reported cooking 15 or more times a week. The proportion of women who reported that their kitchens were occasionally or often filled with heavy cooking fumes were $18 \%$ and $3 \%$ respectively.

Compared with women who did not have any smokers in the household, women exposed to passive smoking had significantly higher prevalences of chronic cough and phlegm, breathlessness on exertion, and wheezing (table II). Women with heavy exposure to smoke, in particular, were found to have the most significantly greater prevalences of these respiratory symptoms. The relative odds of association remained statistically significant after allowing for possible confounding by age, race, area of residence, flat size, and employment status.

Although the differences in the prevalences of respiratory symptoms in relation to the weekly frequency of gas cooking were not statistically significant, most of the estimated relative odds

Table I Demographic characteristics of nonsmoking women, Singapore Respiratory Health Study

\begin{tabular}{llllll}
\hline & \multicolumn{2}{l}{ All women } & \multicolumn{2}{l}{ Housewives only } \\
\cline { 2 - 3 } & No & $(\%)$ & & No & $(\%)$ \\
\hline No of subjects & 1282 & $(100)$ & & 548 & $(100)$ \\
Housing estate: & & & & \\
$\quad$ Bukit Merah & 202 & $(15 \cdot 8)$ & & 87 & $(15 \cdot 9)$ \\
$\quad$ Geylang/Eunos & 304 & $(23 \cdot 7)$ & & 137 & $(25 \cdot 0)$ \\
Jurong East & 329 & $(25 \cdot 7)$ & & 121 & $(22 \cdot 1)$ \\
$\quad$ Toa Payoh & 192 & $(15 \cdot 0)$ & & 91 & $(16 \cdot 6)$ \\
$\quad$ Yishun & 255 & $(19 \cdot 9)$ & & 112 & $(20 \cdot 4)$ \\
Age (y): & & & & \\
$\quad$ 20-39 & 552 & $(43 \cdot 0)$ & & 129 & $(23 \cdot 5)$ \\
$\quad$ 40-59 & 479 & $(37 \cdot 4)$ & 248 & $(45 \cdot 3)$ \\
$\quad$ 60-75 & 251 & $(19 \cdot 6)$ & 171 & $(31 \cdot 2)$ \\
Race: & & & & \\
$\quad$ Chinese & 441 & $(34 \cdot 4)$ & & 173 & $(31 \cdot 2)$ \\
$\quad$ Malays & 431 & $(33 \cdot 6)$ & 182 & $(33 \cdot 2)$ \\
$\quad$ Indians & 410 & $(32 \cdot 0)$ & 193 & $(35 \cdot 2)$ \\
Flat size: & & & & \\
$\quad$ 1-3 rooms & 801 & $(62 \cdot 5)$ & 367 & $(67 \cdot 0)$ \\
$\quad$ or more rooms & 481 & $(37 \cdot 5)$ & 181 & $(33 \cdot 0)$ \\
\hline
\end{tabular}

tended to exceed unity, and the increased prevalence of breathlessness on exertion in particular was of borderline statistical significance (table III). It is interesting to note that, given the possibility of reporting bias, the prevalences of most of these symptoms were significantly greater in women who reported that their kitchens were frequently (compared with rarely) filled with heavy cooking fumes, particularly for chronic cough and phlegm (relative odds $4 \cdot 04 ; 95 \%$ CI $1 \cdot 44,11 \cdot 34$ ), chronic bronchitis (relative odds $6 \cdot 17 ; 95 \%$ CI $2 \cdot 43$, 15.64), and breathlessness on exertion (relative odds $1 \cdot 84 ; 95 \%$ CI $1 \cdot 12,3 \cdot 01$ ).

The mean values of $\mathrm{FEV}_{1}$ and $\mathrm{FEV}_{1} \%$ of predicted were lower in women who had one or more smokers at home (table IV) Similar statistically significant differences were observed in women who cooked frequently (more than twice a week). No significant differences were found when comparing the frequency with which kitchens were reportedly filled with heavy fumes.

Most of these associations were also consistently seen in housewives, although the confidence intervals of the associations were much wider because of smaller numbers of observations.

\section{Discussion}

These results provide further evidence of a positive association between passive smoking and respiratory symptoms and lung function impairment in non-smoking adults. Not all the available evidence from a number of studies supports the presence of such an effect, but our results agree with those reported in several investigations. ${ }^{29} 30{ }^{32-35}$ Higher prevalences of chronic cough and phlegm were most clearly seen in those women with household members who were heavy smokers. In women living with household members who were light smokers, some effects were also apparent, especially with regard to usual cough in the morning, day, or night. It is interesting to note that many more women reported "usually" having a cough, but not for "as much as three months in the year". Considering the nature of passive exposure to cigarette smoke, it is reasonable to expect that most affected women
Table II Prevalence \% (no) and adjusted rate ratio $(95 \% \mathrm{CI})$ of association between respiratory symptoms and exposure to smoke at home by non-smoking women

\begin{tabular}{|c|c|c|c|c|c|}
\hline & \multicolumn{3}{|c|}{ Ever exposed to smokers at home } & \multicolumn{2}{|c|}{ Adjusted rate ratio $*(95 \% \mathrm{CI})$} \\
\hline & None & $\begin{array}{l}1 \text { or more } \\
\text { light smokers }\end{array}$ & $\begin{array}{l}1 \text { or more } \\
\text { heavy smokers }\end{array}$ & $\begin{array}{l}1 \text { or more light } \\
\text { smokers } \mathrm{v} \text { none }\end{array}$ & $\begin{array}{l}1 \text { or more heavy } \\
\text { smokers } \mathrm{v} \text { none }\end{array}$ \\
\hline \multicolumn{6}{|c|}{ All employed women and housewives: } \\
\hline No of subjects & 619 & 344 & 319 & & \\
\hline Usual cough & $1 \cdot 8(11)$ & $4 \cdot 6(16)$ & $6 \cdot 3(20)$ & $2 \cdot 84(1.29,6 \cdot 24) \ddagger$ & $3.79(1 \cdot 76,8 \cdot 14) \ddagger$ \\
\hline Usual phlegm & $4 \cdot 7(29)$ & $6 \cdot 1(21)$ & $5 \cdot 3(17)$ & $1.50(0.83,2.71)$ & $1.36(0.72,2.57)$ \\
\hline Cough 3 months & $1 \cdot 1(7)$ & $1 \cdot 2(4)$ & $3 \cdot 4(11)$ & $1.08(0.31,3.72)$ & $3.01(1.13,8.03) \ddagger$ \\
\hline Phlegm 3 months & $1.8(11)$ & $1 \cdot 2(4)$ & $3 \cdot 1(10)$ & $0.74(0.23,2.37)$ & $2.29(0.94,5.59)$ \\
\hline Chronic bronchitis & $1 \cdot 8(11)$ & $1.4(5)$ & $3.8(12)$ & $0.91(0.31,2.66)$ & $2.25(0.96,5.27)$ \\
\hline Breathlessness & $18 \cdot 7(117)$ & $20 \cdot 6(71)$ & $26 \cdot 6(85)$ & $1.23(0.87,1.74)$ & $1.83(1.30,2.58) \ddagger$ \\
\hline Wheeze & $2.4(15)$ & $2 \cdot 3(8)$ & $5.0(16)$ & $0.95(0.38,2.39)$ & $2 \cdot 69(1.23,5 \cdot 88) \ddagger$ \\
\hline $\begin{array}{l}\text { Physician } \\
\text { diagnosed asthma }\end{array}$ & $2 \cdot 4(15)$ & $2 \cdot 0(7)$ & $3 \cdot 4(11)$ & $0 \cdot 86(0 \cdot 34,2 \cdot 21)$ & $1.60(0.69,3 \cdot 70)$ \\
\hline \multirow{2}{*}{\multicolumn{6}{|c|}{ Housewives only: }} \\
\hline No of subjects & 279 & 136 & & & \\
\hline Usual cough & $2 \cdot 1(6)$ & $5 \cdot 1(7)$ & $6 \cdot 0(8)$ & $2.53(0.81,7 \cdot 87)$ & $3.08(1.01,3.48) \dagger$ \\
\hline Usual phlegm & $6 \cdot 1(17)$ & $8 \cdot 1(11)$ & $6 \cdot 0(8)$ & $1.59(0.71,3.57)$ & $1.18(0.48,2.95)$ \\
\hline Cough 3 months & $1.8(5)$ & $1.5(2)$ & $3 \cdot 8(5)$ & $0.65(0.12,3.56)$ & $1.61(0.43,6.04)$ \\
\hline Phlegm 3 months & $2.9(8)$ & $1.5(2)$ & $3.0(4)$ & $0.56(0.11,2 \cdot 74)$ & $1.35(0.38,4.80)$ \\
\hline Chronic bronchitis & $2.9(8)$ & $0 \cdot 7(1)$ & $4.5(6)$ & $0.26(0.03,2.09)$ & $1.54(0.50,4.74)$ \\
\hline Breathlessness & $20 \cdot 1(56)$ & $24 \cdot 3(33)$ & $27 \cdot 1(36)$ & $1.45(0.85,2.48)$ & $1.89(1.09,3.26) \dagger$ \\
\hline Wheeze & $3.6(10)$ & $2.9(4)$ & $5 \cdot 3(7)$ & $0.64(0 \cdot 17,2 \cdot 42)$ & $1.71(0.51,5.66)$ \\
\hline $\begin{array}{l}\text { Physician } \\
\text { diagnosed asthma }\end{array}$ & $3.6(10)$ & $2 \cdot 2(3)$ & $3 \cdot 8(5)$ & $0.60(0.15,2.44)$ & $0 \cdot 88(0 \cdot 25,3 \cdot 06)$ \\
\hline
\end{tabular}

^Adjusted for age, race, area of residence, flat size, employment status, and weekly frequency of gas cooking.

$\nmid \mathrm{p}<0 \cdot 05 ; \neq \mathrm{p}<0 \cdot 01$

See text for explanations of symptoms 
Table III Prevalence \% (no) and adjusted rate ratio $(95 \%$ CI) of association between respiratory symptoms and weckly frequency of gas cooking by non-smoking aiomen
Table II Forced expiratory zolume in on second ( $\mathrm{FEV}^{2}$ ), (mean SEMI), of nom-smoking atomen in relation to domestic exposure to cigarette smoke and gas cooking

\begin{tabular}{|c|c|c|c|c|c|}
\hline & \multicolumn{3}{|c|}{ Weekly frequency of gas cooking } & \multicolumn{2}{|c|}{ Adjusted rate ratio ${ }^{*}(95 \% \mathrm{CI})$} \\
\hline & $0-2$ times & 3-14 times & $>=15$ times & $\begin{array}{l}3-14 \text { times } \mathrm{v} \\
0-2 \text { times }\end{array}$ & $\begin{array}{l}>=15 \text { times } \mathrm{v} \\
0-2 \text { times }\end{array}$ \\
\hline \multicolumn{6}{|c|}{ All employed women and housewives: } \\
\hline No of subjects & 266 & $64 \overline{7}$ & 369 & & \\
\hline Usual cough & $3 \cdot 0(8)$ & $3 \cdot 2(21)$ & $4 \cdot 9(18)$ & $1.17(0.49,2.77)$ & $1.51(0.59,3.85)$ \\
\hline Usual phlegm & 4.9 (13) & $5 \cdot 6(36)$ & $4.9(18)$ & $1.12(0.57,2.23)$ & $0.85(0.37,1.93)$ \\
\hline Cough 3 months & $1 \cdot 1(3)$ & $2 \cdot 0(13)$ & $1 \cdot 6(6)$ & $1.65(0.44,6.15)$ & $1.13(0.25,5 \cdot 06)$ \\
\hline Phlegm 3 months & $1 \cdot 1(3)$ & $2 \cdot 3(15)$ & $1.9(7)$ & $2.08(0.57,7.57)$ & $1 \cdot 89(0 \cdot 43,8 \cdot 26)$ \\
\hline Chronic bronchitis & $1 \cdot 1(4)$ & $2 \cdot 8(18)$ & $1.6(6)$ & $1.80(0.58,5.60)$ & $0.89(0.23,3.51)$ \\
\hline Breathlessness & $16.9(+5)$ & $21.9(142)$ & $23 \cdot 3(86)$ & $1 \cdot 46(0 \cdot 98,2 \cdot 17)$ & $1.43(0.91,2.15)$ \\
\hline Wheeze & $1.5(4)$ & $3.5(23)$ & $3 \cdot 2(12)$ & $2.36(0.76,7.36)$ & $1.66(0.48,5.79)$ \\
\hline $\begin{array}{l}\text { Physician } \\
\text { diagnosed asthma }\end{array}$ & $1 \cdot 5(4)$ & $2 \cdot 2(14)$ & $4 \cdot 1(15)$ & $1 \cdot 44(0 \cdot 45,4 \cdot 62)$ & $2 \cdot 54(0 \cdot 76,8 \cdot 44)$ \\
\hline \multicolumn{6}{|l|}{ Housewives only: } \\
\hline Usual cough & $1 \cdot 6(1)$ & $3 \cdot 0(8)$ & $5 \cdot 6(12)$ & $1 \cdot 84(0 \cdot 22,15 \cdot 58)$ & $3.16(0.37,26 \cdot 65)$ \\
\hline Usual phlegm & $6 \cdot 3(4)$ & $7 \cdot 4(20)$ & $5.6(12)$ & $1.18(0.37,3.72)$ & $0.75(0.21,2.64)$ \\
\hline Cough 3 months & $1 \cdot 6(1)$ & $2 \cdot 2(6)$ & $2 \cdot 3(5)$ & $0.91(0.10,8.40)$ & $1 \cdot 10(0.12,10 \cdot 34)$ \\
\hline Phlegm 3 months & $1 \cdot 6(1)$ & $3 \cdot 3(9)$ & $1.9(4)$ & $2.51(0.30,21 \cdot 22)$ & $1.81(0.19,17.51)$ \\
\hline Chronic bronchitis & $1.6(1)$ & $3 \cdot 7(10)$ & $1.9(4)$ & $2.02(0.24,16.84)$ & $0.98(0.10,9.57)$ \\
\hline Breathlessness & $14 \cdot 3(9)$ & $21 \cdot 8(59)$ & $26 \cdot 5(57)$ & $1.85(0.81,4.23)$ & $2.28(0.99,5.32)$ \\
\hline Wheeze & $4 \cdot 8(3)$ & $5.9(16)$ & $6.5(14)$ & $1.55(0.28,8.67)$ & $0.58(0 \cdot 10,3 \cdot 70)$ \\
\hline $\begin{array}{l}\text { Physician } \\
\text { diagnosed asthma }\end{array}$ & $1 \cdot 6(1)$ & $3 \cdot 0(8)$ & $4 \cdot 2(9)$ & $1.87(0.21,16.64)$ & $2 \cdot 85(0.31,26 \cdot 24)$ \\
\hline
\end{tabular}

* Adjusted for age, race, area of residence, flat size, employment status, exposure to smokers at home, and atopy (for wheeze and physician diagnosed asthma). See text for explanations of symptoms

\begin{tabular}{|c|c|c|c|c|c|c|}
\hline & \multicolumn{3}{|c|}{ All cmploved atomen and houserites } & \multicolumn{3}{|c|}{ Houserities only } \\
\hline & $\begin{array}{l}\text { No of } \\
\text { subjucts }\end{array}$ & $\begin{array}{l}\text { Adjusted } \\
F E V_{1}, L\end{array}$ & $\begin{array}{l}\text { Adjusted } \\
F E \mathrm{~V}^{*},{ }_{0}\end{array}$ & $\begin{array}{l}\text { No of } \\
\text { subjicts }\end{array}$ & $\begin{array}{l}\text { Adjusted } \\
F E V_{1}, L\end{array}$ & $\begin{array}{l}\text { Adjusted } \\
\text { FEL }_{i}\end{array}$ \\
\hline \multicolumn{7}{|l|}{ Smokers at home: } \\
\hline None & 485 & $1.83(0.019)$ & $101.5(1.09)$ & 198 & $1.77(0.035)$ & $103 \cdot 9(2 \cdot 08)$ \\
\hline One or more light smokers & 269 & $1.78(0.026)^{\star}$ & $98 \cdot 1(1 \cdot 44)$ & 92 & $1.66(0.047)^{\star}$ & $97.0(2 \cdot 81)^{\star}$ \\
\hline One or more heary smokers & 254 & $1.76(0.026) t$ & $98 \cdot 3(1 \cdot 46)$ & 104 & $1.62(0.46) t$ & $96.7(2.75)^{\star}$ \\
\hline \multicolumn{7}{|l|}{ Cooking frequency: } \\
\hline o-2 times a week & 196 & $1.85(0.030)$ & $102 \cdot 2(1 \cdot 69)$ & 39 & $1.82(0.068)$ & $106 \cdot 1(4 \cdot 06)$ \\
\hline 3-14 times a week & 511 & $1.77(0.019)^{\star}$ & $99 \cdot 0(1.07)$ & 192 & $1.62(0.033) \dagger$ & $96.1(1.99)^{\star}$ \\
\hline$>=15$ times a week & 301 & $1.75(0.024)^{\star}$ & $96.6(1.35)^{\star}$ & 163 & $1.61(0.035) \dagger$ & $95.4(2.09)^{\star}$ \\
\hline
\end{tabular}

All adjustments were made for area of residence, flat size, emplovment status, and variables in the table as appropriate ${ }^{\star} \mathrm{p}<0 \cdot 05 ; \mathrm{tp}<0 \cdot 01$

would occasionally experience repeated subacute "irritant bronchitis", and depending on the intensity and duration of the exposure, some of them might experience recurrent "chronic bronchitis" more frequently.

Greater prevalences of breathlessness on exertion and wheezing were also found to be associated with passive smoking, and this was corroborated by the lower level of lung function found in passive smokers. It is also interesting to note that these associations with passive smoking were consistently shown in housewives who had never been in paid employment. This clearly implicates household exposure as a major source of passive smoking among women in Singapore. In view of the stringent legislative prohibition on smoking already implemented in public places, including places of work, the greater challenge for the control of passive smoking lies in targeting the home environment, for which legislative control is impossible and public education is essential.

In this present study, a clear association with the frequency of gas cooking was not found for respiratory symptoms, except for breathlessness on exertion. The latter was also corroborated by the finding of lower lung function level in those who frequently cooked by gas. The frequency of gas cooking, however, may not reflect sufficiently accurately the exposure to nitrogen dioxide to serve as a good surrogate indicator, because of a possible wide variation in natural and forced ventilation in homes. By using the reported presence of heavy cooking fumes as an alternative indicator of exposure, however, an increased prevalence of respiratory symptoms was found to be associated with frequent exposure to heavy cooking fumes.

It is possible that this exposure reflects higher nitrogen dioxide exposure from the use of gas stoves because of poor ventilation, but at the same time it may also reflect co-exposure to cooking oil mists and other thermal combustion products of cooking. Cooking oil (palm oil, peanut oil, and other vegetable oils) and animal fats are commonly used in large quantities in Asian cooking (especially Chinese wok cooking). These together with spices and chillies (Indian and Malay cooking) produce oil mists and pungent fumes that may irritate the mucous membranes when food is being prepared (typically under high temperatures). The effect on lung function using this exposure indicator is not so clearly shown, although among housewives, lower lung function in those with frequent exposure to heavy fumes was observed with borderline statistical significance.

It is possible that interviewee bias played a role in explaining the greater symptoms prevalence in those who reported heavy fume exposure. However, the lung function effect observed in those with high weekly frequency of gas cooking is not likely to be explained by this bias.

These results agree with those from a small number of investigations of adults that showed positive associations between gas cooking and respiratory symptoms 283637 and lung function. ${ }^{37}$ 39 Further studies are, however, required to elucidate the precise role of cooking oil mists and organic fumes on the respiratory health of Asian subjects. Nevertheless, it would seem 
prudent to recommend that public health education for the protection of respiratory health should include adequate ventilatory measures to reduce noxious exposure from gas stoves and cooking fumes as much as possible.

This study was made possible by a research grant from the National University of Singapore.

1 Samet JM, Marbury MC, Spengler JD. Health effects and sources of indoor air pollution. Part 1. Am Rev Respir Dis 1987; 136: 1486-508.

2 Samet JM, Marbury MC, Spengler JD. Health effects and sources of air pollution. Part 2. Am Rev Respir Dis 1987; 137: $221-42$

3 Cameron P, Kostin JS, Zaks JM, et al. The health of smokers' and non-smokers' children. Foumal of Allergy 1969; 43: $336-41$

4 Colley JRT, Holland WW, Corkhill RT. Influence of passive smoking and parental phlegm on pneumonia and bronchitis in early childhood. Lancet 1974; ii: 10314.

5 Harlap S, Davies AM. Infant admissions to hospital and maternal smoking. Lancet 1974; i: 529-32.

6 Leeder SR, Corkhill R, Irwig LM, Holland WW, Colley JRT Influence of family factors on the incidence of lower respiratory illness during the first year of life. British foumal of Preventive Medicine 1976; 30: 203-12

7 Melia RJW, Florey C du V, Chinn S. The relation betwee respiratory illness in primary school children and the use of gas for cooking. I. Results from a national survey. Int Epidemiol 1979; 8: 333.8

8 Florey C du V, Melia RJW, Chinn S, et al. The relation between respiratory illness and the use of gas for cooking. III Vitrogen dioxide, respiratory illness and lung infection. Int $\mathcal{F}$ Epidemiol 1979; 8: 347-53.

9 Speizer FE, Ferris B Jr, Bishop YMM, Spengler J. Respiratory disease rates and pulmonary function in children associated with $\mathrm{NO}_{2}$ exposure. Am Rev Respir Dis 1980; 121: $3-10$

10 Fergusson DM, Horwood LJ, Shannon FT. Parental smoking and respiratory illness in infancy. Arch Dis ('hild $1980 ; 55$ : $358-61$.

11 Lebowt\% MD, Burrows B. Respiratory symptoms related to smoking habits of family adults. Chest 1976; 69: 4850 .

12 Colley JRT. Respiratory symptoms in children and parenta smoking and phlegm production. BMF 1974; 2: 2104

3 Weiss ST, Tager IB, Speizer FE, Rosner B. Persistent wheeze. Its relationship to respiratory illness, cigarett smoking, and level of pulmonary function in a population sample of children. Am Rev Respir Dis 1980; 122: 697707.

14 Ware JH, Dockery DW, Spiro A III, Spezer FE, Ferris BG Jr Passive smoking, gas cooking and respiratory health of children living in six cities. Am Rev Respir Dis 1984; 129 36674

15 Weiss ST, Tager IB, Speizer FE, Rosner B. Persistent wheeze. Its relationship to respiratory illness, cigarette smoking, and level of pulmonary function in a population smoking, and level of pulmonary function in a population

sample of children. Am Rev Respir Dis 1980; 122: 697707. parental cigarette smoking on the pulmonary function of parental cigarette smoking on the pulmonary
children. Am f Epidemiol 1979; 110: 15-26.

17 Vedal S, Schenker MB, Samet JM, Speizer FE. Risk factor for childhood respiratory disease: analysis of pulmonary function. Am Rev Respir Dis 1984; 130: 186-92.

18 Tager IB, Weiss ST, Munoz A, Rosner B, Spezer FE. Longitudinal study of the effects of maternal smoking on pulmonary function in children. $N$ Engl 7 Med 1983; 309. pulmonary

19 Taskin DP, Clark VA, Simmons M, et al. The UCLA population studies of chronic obstructive respirator disease: relationship between parental smoking and children's lung function. Am Rev Respir Dis 1984; 129 . 891.7.

20 Hasselblad U, Humble CG, Graham MG, Anderson HS Indoor environment determinants of lung function in children. Am Rev Respir Dis 1981; 123: 479-85.
21 Burchfield CM, Higgins MW, Keller JB, Howatt FW, Butler WJ, Higgins ITT. Passive smoking in childhood: respiratory conditions and pulmonary function in Tecumseh, Michigan. Am Rec Respir Dis 1986; 133:

22 Dodge $R$. The effects of indoor pollution on Arizona children. Arch Enciron Health 1982; 37: 151-5.

23 Ekwo EE, Weinberger MW', I achenbruch PA, Huntley WH. Relationship of parental smoking and gas cooking to respiratory disease in children. Chest 1983; 84: 66288.

24 Keller MD, Lanese RR, Mitchell RJ, Cote RW. Respiratory illness in households using gas and electricity for cooking. II Svmptoms and objective findings. Environ Red 1979; 19: 504-15.

25 Ogston SA, Florey CV, Walker $\mathrm{CH}$. The Tayside infant morbidity and mortality study: effect on health of using gas for cooking. BMIf 1985; 290: 957-60.

26 Schenker MB, Samet JM, Speizer FE. Risk factors for childhood respiratory disease: the effects of host factors and home environmental exposures. Am Rev Respir Dis 1983; 28: 103843

27 Schilling RSF, Letai AD, Hui SL, Beck GJ, Schoenberg JB, Bouhuys A. Lung function, respiratory disease, and smoking in families. Am F lipidimiol 1977; 106: 27483.

28 Comstock GW, Mever MB, Helsing KJ, Tockman MS. Respiratory effects of household exposures to tobacco smoke and gas cooking. Am Rer Respir Dis 1981; 124: $143-8$

29 Gillis CR, Hole DJ, Hawthorne VM, Boyle P. The effect of environmental tobacco smoke in two urban communities in the West of Scotland. Liw F Respir Dis 1984; 65 (suppl) 133: $121-6$

30 Euler GL, Abbey DE, Magic AR, Hodgkin JE. Chronic obstructive disease symptom effects of long term cumulative exposure too ambient levels of total suspended particulates and sulphur dioxide in Californian Seventhparticulates and sulphur dioxide in Californian Seventh21322.

31 Brunekreef B, Fisher P, Remjin B, Van der I ende R, Schouten J, Quanjer P. Indoor air pollution and its effects on pulmonary function of adult non-smoking women. III. Passive smoking and pulmonary function. Int 7 Iipidemiol 1985; 14: $225-30$

32 White JR, Freob H. Small airways dysfunction in nonsmoker chronically exposed to tobacco smoke. $N^{\prime}$ Engl f Med 1980; 302: 720 .

33 Kauffman F, Tessier JF, Oriol P. Adult passive smoking in the home environment: a risk factor for chronic airflow limitation. Am f Epidemiol 1983; 117: 269-80.

34 Masi JA, Hanley JA, Ernst P, Becklake MR. Environmental exposure to tobacco smoke and lung function in young adults. Am Rev Respir Dis 1988; 138:296-9.

35 Masjedi MR, Kazemi H. Hohnson DC, Effects of passive smoking on the pulmonary function of adults. Thorax 1990; 45: 2731 .

36 Helsing KH, Comstock GW, Meyer MB, Tockman ML. Respiratory effects of household exposure to tobacco smoke and gas cooking in non-smokers. Linviron Int 1982; 8: 365-70.

37 Viegi (j, Paoletti P, Carroz;i M, et al. Effects of home environment on respiratory symptoms and lung function in a general population sample in north Italy. Lur Respir 7 $1991 ; 4: 5806$.

38 Jones JR, Higgins IT'I, Higgins MW, Keller JB. Effects of cooking fucls on lung function in nonsmoking women. Arch Envirom Health 1983; 38: 21922 .

39 Fisher P, Remjin B, Brunckreef B, Van der Lende R, Shouten J, Quanjer $P$. Indoor air pollution and its effects on
pulmonary function of adult nonsmoking women. II. pulmonary function of adult nonsmoking women. II. Association between nitrogen dioxide

40 Gunawardena KA, Houston K, Smith AP. Evaluation of turbine pocket spirometer. Thorax 1987; 42:689-93.

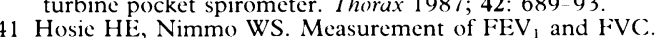
Comparison of a pocket spirometer with the Vitalograph. Ancesthesia 1988; 43: 233-8.

42 Strachan DP, Cox BD, Erzinclioglu S, Walters DE, Whichelow MJ. Ventilatory function and winter fresh fruit consumption in a randonm sample of British adults. Thorax 1991; 46: 624-9. 